\title{
POSTOPERATIVE TREATMENT OF INTERNALLY FIXED ANKLE FRACTURES
}

\author{
A PROSPECTIVE RANDOMISED STUDY \\ C. J. H. M. VAN LAARHOVEN, J. D. MEEUWIS, C. VAN DER WERKEN \\ From the St Elisabeth Hospital, Tilburg and the Academic Hospital, Utrecht, The Netherlands
}

In a prospective, randomised trial of 81 patients with fractures of the ankle of $\mathrm{AO}$ types $\mathrm{A}, \mathrm{B}$ and $\mathrm{C}$ we compared two regimes of postoperative management after internal fixation. The patients were mobilised either non-weight-bearing with crutches or weightbearing in a below-knee walking plaster.

We found a temporary benefit in subjective evaluation only ( $65 v 50$ points, Mann-Whitney test, cft, $\mathbf{p}=\mathbf{0 . 0 2}$ ) for those with a below-knee walking plaster. There were no significant differences between the groups in the loaded dorsal range of movement $\left(25^{\circ} v 23^{\circ}\right.$, Mann-Whitney test, $\mathbf{c f t}, \mathbf{p}=\mathbf{0 . 1 6}$ ) or in the overall clinical result. Both treatments were considered to be satisfactory and their choice depends on the ability to mobilise non-weight-bearing, wound healing, the type of work and personal preference.

J Bone Joint Surg [Br] 1996;78-B:395-9.

Received 8 March 1995; Accepted after revision 19 December 1995

The standard postoperative management advised by the Association for the Study of Internal Fixation (Müller et al 1969) after the internal fixation of fractures of the ankle is the use of crutches without weight-bearing. It is based on the principle of early active painfree mobilisation of muscles and joints adjacent to the fracture for the prevention of 'fracture disease'.

C. J. H. M. van Laarhoven, MD, PhD, Surgeon

C. van der Werken, MD, PhD, Surgeon

Department of Surgery, Academic Hospital, Heidelberglaan 100, 3584CX Utrecht, The Netherlands.

J. D. Meeuwis, MD, PhD, Surgeon

Department of Surgery, St Elisabeth Hospital, Tilburg, The Netherlands.

Correspondence should be sent to Dr C. J. H. M. van Laarhoven at Nicolaastraat 5,3512 XD Utrecht, The Netherlands.

(C)1996 British Editorial Society of Bone and Joint Surgery 0301-620X/96/31189\$2.00
In several studies using ASIF operative techniques alternative regimes of treatment after operation have been described. Weber (1972) mobilised patients after wound healing with an orthosis in which the weight was partially transmitted to the lower leg with a spring preventing pes equinus. Hanke (1989) used a 'Gehapparat' which is a similar appliance. Lindsjö (1981) applied a below-knee walking plaster.

There have been several prospective randomised trials to compare different types of postoperative treatment. Sondenaa et al (1986) compared two regimes of plaster immobilisation without weight-bearing. Half of the patients had early active exercises and the use of a removable splint; the other half was not allowed to do exercises. The latter had a temporary increase in pain, swelling and loss of the loaded dorsal range of movement, which appears to justify the ASIF principle of early active exercises.

In 1986 and 1987 Ahl et al reported two studies comparing early and late weight-bearing in plaster for unimalleolar and for bimalleolar and trimalleolar fractures. Operation was by Cedell's (1967) method of adaptive osteosynthesis. All patients were kept in plaster for seven weeks and were randomised either to four weeks of mobilisation without weight-bearing and crutches or to direct weight-bearing. They concluded that early weight-bearing in a below-knee walking plaster was safe, but because of a small risk of superficial wound infection, they advised that weight-bearing should begin after primary wound healing. In 1988 Ahl, Dalén and Selvik presented a further study comparing early weight-bearing in a below-knee walking plaster with an orthosis which was removed five times daily to exercise the ankle. After three months a higher subjective score and a better loaded dorsal range of movement were found in the orthosis group, but as in other studies, the differences were temporary and had disappeared after one year. After a further randomised trial in 1993 they concluded that there were only small differences in the various types of management and as early active weight-bearing in a walking plaster facilitates rehabilitation, this should be preferred. Cimino, Ichtertz and Slabaugh (1991) found no significant difference in the loaded dorsal range of movement between a group mobilised in a walking plaster and one using a hinged ankle-foot orthosis. 
Table I. Details of 81 patients with ankle fractures

\begin{tabular}{lll}
\hline & $\begin{array}{l}\text { Plaster } \\
\text { (n= 41) }\end{array}$ & $\begin{array}{l}\text { Crutches } \\
\text { (n= 40) }\end{array}$ \\
\hline Median age in years (range) & $35.5(17$ to 77$)$ & $37(15$ to 77) \\
Male:female & $24: 17$ & $21: 19$ \\
Right:left & $18: 23$ & $19: 21$ \\
Cause of fracture & & \\
$\quad$ Traffic & 15 & 10 \\
$\quad$ Sport & 13 & 16 \\
$\quad$ Domestic & 9 & 9 \\
$\quad$ Work & 2 & 2 \\
$\quad$ Other & 2 & 3 \\
History of fracture & 1 & \\
Pre-existing neurological disease & 0 & 1 \\
Soft-tissue injury & & \\
$\quad$ Grade 0 & 41 & 39 \\
$\quad$ Grade I & 0 & 1 \\
\hline
\end{tabular}

Table II. Classification of the fractures according to the AO/ASIF system (Olerud and Molander 1984)

\begin{tabular}{lr}
\hline AO type A fracture & 3 \\
$\quad$ Supination-adduction II & 3 \\
$\quad(=$ AO type A2 and A3) & \\
AO type B fracture & 55 \\
$\quad$ Supination-eversion IV & 51 \\
$\quad$ (= AO type B1-B3) & \\
$\quad$ Pronation-abduction III & 1 \\
$\quad$ (= AO type B3) & \\
$\quad$ Not classifiable & 3 \\
AO type C fracture & 23 \\
$\quad$ Supination-eversion IV & 8 \\
$\quad(=$ AO type C1-C3) & \\
$\quad$ Pronation-eversion III-IV & 15 \\
$\quad(=$ AO type C2) & \\
Total & 81 \\
\hline
\end{tabular}

We have compared non-weight-bearing 'functional' mobilisation with active exercises and crutches with early weight-bearing using a below-knee walking plaster.

\section{PATIENTS AND METHODS}

Between April 1991 and April 1993, we randomised 81 consecutive patients with ankle fractures treated by internal fixation using an odd or even date of accident, to management with either a below-knee walking plaster or with nonweight-bearing mobilisation with crutches. We excluded those with fractures which were assessed as unstable for early mobilisation after the operation (e.g. because of insufficient fixation in severely osteoporotic bone), grade-II and grade-III open fractures (Müller et al 1990), pilon fractures of the tibia, and open injuries to the physeal plate of the distal tibia, and those who were unable to cope with either of the two post-treatment schemes. The details are given in Table I. The fractures were classified according to the $\mathrm{AO} /$
ASIF system (Olerud and Molander 1984), combined with the Lauge Hansen (1942) system (Table II).

Of the 55 patients with AO type-B fractures, 19 (35\%) also had a fracture of the medial malleolus and 26 (47\%) had a deltoid ligament rupture. Twenty-six (47\%) had associated fractures of the posterior malleolus.

In those with $\mathrm{AO}$ type- $\mathrm{C}$ fractures there were ten associated fractures of the medial malleolus, 13 ruptures of the deltoid ligament and 11 fractures of the posterior malleolus.

The fibular implants consisted of lag screws (41 patients), a one-third tubular plate (30), a tension band (4), a tibiofibular syndesmotic positioning screw (4) and a combination of implants (2). An additional positioning screw was used in six. Internal fixation of the medial malleolar fracture was performed in 27 of 29 patients and of the posterior malleolar fracture in 15 of 37 . All positioning screws were removed after a median period of 58 days (46 to 62).

Postoperative management. After rigid internal fixation all patients were treated in a plaster cast for two to five days. After initial wound healing and exercises to prevent equinus and to increase the range of dorsal movement, 41 were randomly allocated to a below-knee walking plaster (17 unimalleolar fractures and 24 bimalleolar or trimalleolar fractures) and 40 to non-weight-bearing with crutches (16 unimalleolar fractures and 24 bimalleolar or trimalleolar fractures). Four of the patients with a positioning screw were in the walking plaster group and six in the other. The median period of hospital admission was six days (2 to 25).

Twenty-three patients received physiotherapy (28\%) in the period between six weeks and one year after the operation. Nine (22\%) had been in a walking plaster and 14 (35\%) on crutches. Two of the patients had Sudeck's dystrophy and were given active exercises. The remaining 21 patients had walking and stabilising exercises, massage (9), ultrasound (2), traction and translation (1), interference (3) and warm compresses (2).

All patients were reviewed at 10 to 14 days, six weeks, three months and one year after operation. After 10 to 14 days the stitches were removed. At each assessment we performed a physical and radiological examination for which lateral and mortise views were taken.

We evaluated the patients subjectively using a modification of the scoring system proposed by Olerud and Molander (1984) (Table III). Patients were also asked to express their complaints, progress in mobilisation and ability to perform everyday activities using a linear analogue scale of 0 to 100. Clinically, they were classified as 'excellent', 'good', 'fair' and 'poor' (Table IV). The loaded dorsal range of movement was measured according to Lindsjö (1981) and the anatomical and radiological features using the criteria of Cedell (1967).

The loaded dorsal range of movement was measured by standing the patient on a small elevated box with the knee and hip flexed. Both ankles were measured. The width of the medial joint line was assessed. Measurements of supination and pronation were not carried out as these movements 
Table III. The modified subjective ankle score of Olerud and Molander (1984)

\begin{tabular}{|c|c|}
\hline & Score \\
\hline \multicolumn{2}{|l|}{ Pain } \\
\hline None & 25 \\
\hline Minor (weather-dependent) & 20 \\
\hline During sports & 15 \\
\hline During walking on smooth surfaces & 5 \\
\hline Constant and severe & 0 \\
\hline \multicolumn{2}{|l|}{ Stiffness } \\
\hline None & 10 \\
\hline In the morning & 5 \\
\hline Constant & 0 \\
\hline \multicolumn{2}{|l|}{ Swelling } \\
\hline None & 10 \\
\hline Only in the evening & 5 \\
\hline Constant & 0 \\
\hline \multicolumn{2}{|l|}{ Star-climbing } \\
\hline No problems & 10 \\
\hline Impaired & 5 \\
\hline Impossible & 0 \\
\hline \multicolumn{2}{|l|}{ Sports } \\
\hline Normal & 10 \\
\hline Impaired & 5 \\
\hline Impossible & 0 \\
\hline \multicolumn{2}{|l|}{ Supports } \\
\hline None & 10 \\
\hline Tape or wrap & 5 \\
\hline Stick or crutch & 0 \\
\hline \multicolumn{2}{|l|}{ Daily activity and work } \\
\hline Unchanged level & 25 \\
\hline Loss of tempo & 20 \\
\hline Change to easier job or part-time job & 10 \\
\hline $\begin{array}{l}\text { Severely impaired work capacity } \\
\text { or disability to work }\end{array}$ & 0 \\
\hline Total & 100 \\
\hline
\end{tabular}

are mainly located in the subtalar ankle joint and in the middle and forefoot (Zwipp 1989). The Cedell (1967) classification describes the separate results of the lateral, medial and posterior malleoli in terms of dislocation in millimetres. Osteoarthritis was assessed by observation of narrowing of the joint space, osteophyte formation and early ligamentous calcification.

Statistical analysis. The results are expressed as the median and the range with, if appropriate, the $95 \%$ confidence interval (CI) estimated according to Day (1988) and Gardner and Altman (1989). It was not possible to undertake blind assessment of the treatment groups. As a normal distribution cannot be assumed only non-parametric tests were used. For qualitative data we used Fisher's exact test (two samples, two-tailed) and for quantitative data the Mann-Whitney test (two samples, with correction for ties). A significance level $=0.05$ was assumed.

\section{RESULTS}

Complications. Complications occurred in 13 patients (16\%). These were superficial wound infection (6), osteitis (1), secondary dislocation after operation (3), delayed union (1) and Sudeck's dystrophy (2). Further operation was needed in two patients. The cases of infection were equally divided between the walking plaster group with four superficial wound infections and the non-weight-bearing group with two superficial wound infections and one case of osteitis. There was one case of wound dehiscence in each group. Postoperative management. One patient was lost to follow-up after three months. Another developed haemorrhagic pancreatitis two months after the ankle fracture and the data were therefore incomplete, but assessment was possible at 20 months.

The median subjective ankle score at the final review (median 12 months) was 95 points (35 to 100). Comparison of the AO type-B and type-C groups showed no difference in the median scores: 95 points and 100 points, respectively

Table IV. Classification of the clinical results

\begin{tabular}{|c|c|c|c|c|}
\hline Score & I Poor* & II Fair $\dagger$ & III Good & IV Excellent \\
\hline Complaints & Pain at work/rest & Pain at sports & Minor & None \\
\hline Activity/work & Unable to work & Changed & Unchanged & Unchanged \\
\hline $\begin{array}{l}\text { Loss of loaded dorsal range of } \\
\text { motion (degrees) }\end{array}$ & $>20$ & 11 to 20 & 4 to 10 & 0 to 3 \\
\hline Cedell's classification & $<$ Poor/./. & $\geq$ Poor/./. & $\geq \mathrm{Good} / \mathrm{G} / \mathrm{G} \ddagger$ & Anatomical/A/A $\ddagger$ \\
\hline Medial clear space widening $(\mathrm{mm})$ & $>2$ & $=2$ & $\leq 1$ & $=0$ \\
\hline Osteoarthritis & $\begin{array}{l}\text { Narrowing } \\
>1 / 2\end{array}$ & $\begin{array}{l}\text { Sclerosis/cysts } \\
\text { Narrowing }<1 / 2\end{array}$ & Osteophytes & No signs \\
\hline
\end{tabular}


Table V. Results and differences in the median loss of loaded dorsal range of movement, the median linear analogue scale and the median subjective ankle score at each follow-up (Mann-Whitney test, cft*)

\begin{tabular}{|c|c|c|c|c|c|c|}
\hline \multirow[b]{2}{*}{ Follow-up } & \multicolumn{2}{|c|}{$\begin{array}{l}\text { Loss of loaded dorsal range of } \\
\text { movement (degrees) }\end{array}$} & \multicolumn{2}{|c|}{ Linear analogue scale } & \multicolumn{2}{|c|}{ Subjective ankle score } \\
\hline & Plaster & Crutches & Plaster & Crutches & Plaster & Crutches \\
\hline \multirow[t]{2}{*}{10 days } & 28 & 33 & 40 & 30 & 45 & 40 \\
\hline & & & & & & \\
\hline \multirow[t]{2}{*}{6 weeks } & 25 & 23 & 70 & 60 & 65 & 50 \\
\hline & & & & & & \\
\hline \multirow[t]{2}{*}{3 months } & 14 & 12 & 80 & 80 & 85 & 80 \\
\hline & & & & & & \\
\hline \multirow[t]{2}{*}{1 year } & 8 & 7 & 90 & 90 & 95 & 95 \\
\hline & & & & & & \\
\hline
\end{tabular}

*correction for ties

(Mann-Whitney test, cft, $\mathrm{p}=0.36$ ). There was also no difference between the walking plaster and the non-weight-bearing groups (Mann-Whitney test, $\mathrm{cft}, \mathrm{p}=0.90$ ). Inclusion of the patient who was lost to follow-up also produced no difference between the walking plaster (median 95 points, range 0 to 100) and the non-weight-bearing groups (median 95, range 35 to 100; Mann-Whitney test, cft, $\mathrm{p}=0.94$ ).

The median linear analogue scale score at the final review was 90 in both groups (range 35 to 100; Mann-Whitney test, cft, $\mathrm{p}=0.83$ ). The difference between the clinical scores of the walking plaster $(29 / 40,72.5 \%)$ and the nonweight-bearing groups $(26 / 40,65 \%)$ was not significant (95\% CI of the difference was $12.5 \%$ to $27.5 \%$, chi-squared test, $\mathrm{p}=0.47$ ).

Table $\mathrm{V}$ gives the differences in the loss of loaded dorsal range of movement, the linear analogue scale and the subjective ankle score at each follow-up. Mobilisation in a walking plaster during the first six weeks after operation did not diminish the loaded dorsal range of movement in the ankle. This supports the concept of the 'functional' treatment of operated ankle fractures in a walking plaster; it allows some movement in the joint.

Both the subjective ankle score and the linear analogue score, which are based on the subjective experiences of the patients, had a small difference in favour of the walking plaster group at six weeks $(p=0.03$ and $p=0.02)$. At ten days, however, this group already had a nearly significantly better linear analogue score. Considering also the small differences of the median values and the $p$ values, which are just below 0.05 , these subjective results indicate that no important difference is to be expected at six weeks $(95 \% \mathrm{CI}$ of differences of median linear analogue score at six weeks 0 to $15 ; 95 \%$ CI of differences of median subjective ankle scores at six weeks $0 \%$ to $15 \%$ ). At three months and at one year the differences between the median subjective ankle scores and the analogue scores had disappeared.

Return to work. The median period of return to full-time work was 78 days (9 to 244) for the walking plaster group and 79 days ( 9 days to 1 year) for the non-weight-bearing patients (Mann-Whitney test, cft, $\mathrm{p}=0.54$ ).
Disregarding the type of job, return to work on a parttime basis took a median of 24 days ( 7 to 183) for those in a walking plaster and 44 days ( 4 to 216) for the nonweight-bearing group. This difference was not significant (Mann-Whitney test, $\mathrm{cft}, \mathrm{p}=0.19$ ). Patients with a standing job required a median period of 20 days in the walking plaster group and 40 days in the non-weight-bearing group (difference not significant, Mann-Whitney test, $\mathrm{cft}, \mathrm{p}=$ $0.13)$.

Secondary dislocation and radiological appearance. Secondary dislocation due to injury in the unprotected nonweight-bearing group or to breakage of the implants in those in plaster may influence the radiological appearance, the morbidity and the end result. The three cases of secondary dislocation occurred within the first ten days before mobilisation with crutches or weight-bearing in a walking plaster was begun. The type of treatment after operation did not affect the anatomical result. The final review showed a 'good or anatomical' radiological appearance (Cedell group I or II) in all cases, with medial clear space widening of 1 $\mathrm{mm}$ or less in all patients. Although no definite conclusion can be drawn from observations of only one year, $85 \%$ (95\% CI $71 \%$ to $93 \%$ ) of the walking plaster group and $98 \%$ (95\% CI $87 \%$ to $100 \%$ ) of the non-weight-bearing group had no signs of osteoarthritis (osteoarthritis scale IV; $95 \%$ CI of the difference $1 \%$ to $25 \%$; Fisher's exact test, twotailed, $\mathrm{p}=0.11$ ).

The effect of physiotherapy on the loaded dorsal range of movement. The median loss of loaded dorsal range of movement decreased from $34^{\circ}$ to $22^{\circ}$ in the group with physiotherapy and from $28^{\circ}$ to $6^{\circ}$ in those without physiotherapy. No conclusion can be drawn from these results as these are selected groups, but clinical observations suggest that physiotherapy had a positive effect on recovery of movement at the ankle.

\section{DISCUSSION}

Although the patients with a walking plaster had a significantly higher linear analogue score and a higher subjective 
ankle score at six weeks, there was no difference afterwards. The loaded dorsal range of movement, as a direct measurement of the effect of immobilisation of the ankle by plaster, showed no difference at any time. The difference in ability to return to work was not significant, although the walking plaster group needed a median of 24 days and the nonweight-bearing group 44 days to restart their work on a parttime basis. The complication rate was equally divided in both groups.

No evidence was found for the general assumption that the mobilisation of patients with an operatively treated ankle fracture in a walking plaster is 'a combination of disadvantages of two treatments'. Our results show that the early application of a walking plaster did not result in an increased rate of complications such as wound dehiscence, superficial wound infection, arthritis, osteitis or secondary dislocation.

No benefits in any form have been received or will be received from a commercial party related directly or indirectly to the subject of this article.

\section{References}

Ahl T, Dalén N, Holmberg S, Selvik G. Early weight bearing of malleolar fractures. Acta Orthop Scand.1986;57:526-9.

Ahl T, Dalén N, Holmberg S, Selvik G. Early weight bearing of displaced ankle fractures. Acta Orthop Scand 1987;58:535-8.
Ahl T, Dalén N, Selvik G. Mobilization after operation of ankle fractures: good results of early motion and weight-bearing. Acta Orthop Scand 1988;59:302-6.

Ahl T, Dalén N, Lundberg A, Bylund C. Early mobilization of operated on ankle fractures. Acta Orthop Scand 1993;64:95-9.

Cedell C-A. Supination-outward rotation injuries of the ankle: a clinical and roentgenological study with special reference to the operative treatment. Acta Orthop Scand 1967;Suppl 110.

Cimino W, Ichtertz D, Slabaugh P. Early mobilization of ankle fractures after open reduction and internal fixation. Clin Orthop 1991;267:152-6.

Day SJ. Clinical trial numbers and confidence intervals of pre-specified size (letter). Lancet 1988;2:1427.

Gardner MJ, Altman DG. Statistics with confidence: confidence intervals and statistical guidelines. London: British Medical Journal, 1989.

Hanke J. Luxationsfrakturen des oberen Sprunggelenkes. Berlin, etc: Springer Verlag, 1989..

Lauge Hansen N. Anklebrud I. Genetisk diagnose of reposition. Dissertation. Munksgaard, Copenhagen, 1942.

Lindsjö U. Operative treatment of ankle fractures. Acta Orthop Scand 1981;52:Suppl 189.

Müller ME, Allgöwer M, Schneider R, Willenegger H. Manual der osteosyntheses, AO-technique. Berlin, etc; Springer Verlag, 1969.

Müller ME, Nazarian S, Koch P, Schatzker J. The comprehensive classification of fractures of long bones. Berlin, etc: Springer-Verlag, 1990.

Olerud C, Molander H. A scoring scale for symptom evaluation after ankle fracture. Arch Orthop Trauma Surg 1984;103:190-4.

Sondenaa K, Hoigaard U, Smith D, Alho A. Immobilization of operated ankle fractures. Acta Orthop Scand 1986;57:59-61.

Weber BG. Die verletzungen des oberen sprunggelenkes. 2nd ed. Berne, etc: Verlag Hans Huber, 1972.

Zwipp H. Biomechanics of the ankle joint. Unfallchirurg. 1989;92: 98-102. 